\title{
Rediscutindo a relação entre música e linguagem a partir das análises de Paolo Virno
}

FLAVIO BARBEITAS

UNIVERSIDADE FEDERAL DE MINAS GERAIS (flaviobarbeitas@ufmg.br)

\section{Breve histórico da relação entre música e linguagem}

$A$ relação entre música e linguagem, como de resto $\mathcal{A}$ comprovam as múltiplas interpretações que ao longo do tempo se fizeram a respeito, é basilar na história cultural do Ocidente e estabelece um fio condutor inquestionável para a colocação da música no quadro geral do saber.

Consideremos, em passagem arriscadamente sintética, a Modernidade. Pode-se dizer que o projeto epistemológico racionalista que inicialmente a fundamentou teve alguma resistência em acolher os desafios que o fenômeno musical apresentava aos mecanismos de compreensão do mundo mais privilegiados pela razão. Principalmente desde que paulatinamente se autonomizou da palavra, a música passou a ser alvo de indagações por parte do conhecimento racionalista em termos que, acima de tudo, revelavam uma tentativa de enquadramento: uma vez independente da linguagem (verbal), o que a música, afinal, representa; o que quer dizer; o que significa; a que se refere? Ou ainda: com a música, o que podemos conhecer, o que nos é dado entender?

Ilustra bem esse estado de coisas o seguinte comentário de Benedito Nunes à abordagem da música na Crítica do Juízo, de Kant:

A indagação kantiana, fortemente resguardada pelo privilégio da linguagem verbal, aproxima-se, pois, da música adotando uma atitude discriminatória. Marca-lhe, como desvantagem, e, portanto, como traços negativos, tudo quanto a diferencia das outras artes e a distancia da expressão verbal. As diferenças consideradas são mais deficiências do que qualidades específicas. (NUNES, 1998, p. 75)

A principal dessas deficiências, "pedra de escândalo para o Racionalismo" segundo o mesmo Benedito Nunes, seria 
a incapacidade de representação. De tal forma a não referencialidade era problemática que, já no Romantismo, a fim de preencher tal lacuna, Hegel - abrindo uma expressiva corrente a que se juntariam posteriormente, por exemplo, Ernst Cassirer e Susanne Langer - idealizou a música como a arte representativa dos sentimentos e dos afetos.

A análise de Mark Evan Bonds (2014) o confirma, mas também demonstra que o caminho para apresentar a música como "linguagem do coração" ou "linguagem dos sentimentos" vinha de antes, e pavimentava-se sobre uma distinção fundamental entre signos universais e arbitrários, tidos como antípodas. De acordo com essa concepção, eram consideradas arbitrárias as conexões entre as palavras e as ideias ou objetos a que se referiam. Prova disso é que as palavras variavam - e muito - de uma língua a outra, ainda que referindo-se ao mesmo objeto. Por outro lado, os sons não verbais (vocalizações alegres ou lamentosas, gemidos etc.), indicando emoções, eram mais naturais, menos variáveis e, portanto, tendentes à universalidade. Tal era, por exemplo, a opinião de René Descartes, em 1629, como se depreende de uma sua carta ao jesuíta Marin Mersenne, em que declarava: "as expressões inarticuladas de paixões transcendem as diferenças entre as várias línguas verbais e, assim, constituem por direito uma língua universal". 0 jesuíta foi levado a concordar e a concluir que "a maior aproximação com uma linguagem 'natural' deveria ser buscada na música, que opera independentemente das palavras" (BONDS, 2014, p. 62).

Os séculos XVII e XVIII foram o palco da passagem dessa noção preliminar - cuja fortuna engloba também o pensamento de Rousseau, devotado a apontar os vínculos essenciais e originários entre música e linguagem - à consideração da música, ela mesma, como uma linguagem específica, com sua sintética e semântica (sentimentos, afetos) próprias. Tratava-se de uma evolução de perspectiva nada trivial e que teve, portanto, consequências para a composição e a prática musicais do período. 0 fato, contudo, é que permanecia insuficiente e vaga a real caracterização da música como linguagem (das emoções ou dos sentimentos), em virtude 
da inconclusa decifração de seu preciso conteúdo semântico desafio que os teóricos não conseguiam superar.

Ciente dessa fraqueza e em contraponto com o romantismo do século XIX em que viveu, período culminante de busca da essência própria e característica de cada arte, Eduard Hanslick, no célebre tratado Do belo musical, encaminhou a questão de maneira bem diferente ao encerrar a música no formalismo. Postulando que, por natureza, ela era apenas som em movimento e não dispunha de qualquer meio para representar o real, Hanslick concluía que sua verdade devia ser buscada apenas na dinâmica das puras e concretas relações sonoras, sob a forma dos "arabescos em movimento", uma célebre metáfora de seu livro.

Esse dilema clássico, com suas idas e vindas, permaneceu influente no século $\mathrm{XX}$, quando ganhou desdobramentos bem variados. 0 seguinte trecho do 216 musicólogo italiano Mario Baroni, que problematiza a hermenêutica musical, dá bem a dimensão do problema no ponto em que o deixara Hanslick e seu formalismo:

Normalmente todo ser humano atribui um sentido a uma ação, a um discurso, a uma imagem, se estão ligados a situações de experiência que anteriormente viveu, conhece, ou que de algum modo solicitam os seus interesses. Também um texto artístico tem sentido e pode ser interpretado na medida em que evoca, direta ou indiretamente, eventos do mundo ou fantasias sobre o mundo, capazes de envolver e sensibilizar. Mas se os sons musicais não se referem a nada, se não evocam imagens de nenhuma espécie, se são sons e permanecem apenas sons, o que há neles de interpretável? E por que deveríamos interpretá-los? (BARONI, 2002, p. 636) ${ }^{1}$

Anteriormente, nesse mesmo texto em que ao fim e ao cabo irá recusar a visão de uma música totalmente não referencial, Baroni relata como o formalismo de origem hanslickiana obteve maior lastro científico - desviando-se um pouco das intenções originais - com as tendências estruturalistas e semióticas que dominaram a musicologia e a

\footnotetext{
${ }^{1}$ Esta e as demais traduções, neste artigo, são minhas.
} 
análise musical nos anos 60 e 70 do século passado, em correspondência, como era de se esperar, com a poética dos compositores vanguardistas do período, radicalmente antiexpressiva e devotada à criação de novos paradigmas estruturais. A hipótese à época era de que a música pudesse apresentar características muito semelhantes às da linguagem verbal e, portanto, ser estudada com o mesmo rigor científico que os linguistas dedicavam à língua. Rigor que acalentava a esperança dos musicólogos de escapar ao recurso das adjetivações e metáforas - muito comum nas interpretações sobre a música, mas que acabava lançando sobre elas a suspeição de subjetividade e de escassa cientificidade. 0 sucesso desses estudos, contudo, esbarraria mais uma vez na dificuldade de assegurar uma semântica musical análoga à privilegiada nas análises estruturalistas da linguística.

Nos anos 80 e 90, em sentido contrário, sob influxo das teorias ditas pós-modernas, a musicologia (renomeada pelos seus seguidores de New Musicology) desenvolveu a prática de atravessar e confrontar o texto musical com temáticas antes consideradas irrelevantes e distantes da "música em si", mas que encontravam-se então pautadas pelas mais variadas disciplinas das Humanidades (sociologia, antropologia, história etc.). 0 aggiornamento musicológico, implícito no nome dado à corrente, teve como um de seus principais propósitos o de obrigar o texto a revelar forças atuantes, ainda que recalcadas, que poderiam estar em desacordo com as supostas intenções do compositor ou mesmo da própria obra, antes e tradicionalmente entendida como sistema relativamente estável e fechado a cuja decifração estaria consagrado o intérprete.

Tudo se passa aqui como se o objetivo de uma crítica musical, não podendo ser mesmo a análise da intenção do texto (pela ausência, inerente à música, do conteúdo semântico), deixasse também de lado a elucidação dos mecanismos e estruturas através dos quais as obras funcionam para, então, abraçar questões como as seguintes: de que modo determinada obra se relaciona com outras obras e outras práticas; o que ela oculta ou reprime; que estratégias sociais, culturais ou políticas 
evidencia e como tudo isso adquire significação num determinado contexto.

Afastada apenas aparentemente das aproximações entre música e linguagem, a Nova Musicologia manteve-se, na realidade, interessada nas questões relacionadas ao processo de significação da música, deslocando-as, contudo, do discurso sonoro para o contexto bem mais amplo da trama sociocultural - e suas infindáveis mediações - que, se de um lado envolve a música, de outro é também por ela construída.

Vale ser ressaltada desse sintético relato histórico a presença de uma constante referência à linguagem - esta entendida, de forma geral, como processo de significação. Tal referência constitui uma espécie de termo de comparação para a música, a tal ponto que a expressão linguagem musical se tornou mais ou menos consensual, mesmo que nem sempre se tenha grande consciência do que ela está a significar e sem que

218 sequer se tenha tanta clareza quanto à música ser ou não uma linguagem.

Seja como for, o que é importante para a discussão deste texto é que a noção de linguagem prevalentemente veiculada na comparação com a música privilegia sobremaneira, a sua função cognitiva, o que tanto a compromete com sua qualidade representativa e seu conteúdo semântico, quanto lhe exalta a função e o valor epistemológico. Claro está que o privilégio dado a essa noção de linguagem já é fruto de uma decisão cultural ocidental muito anterior, tomada, no mínimo, desde o platonismo².

\section{A linguagem como praxis e como performance}

\footnotetext{
2 Não é possível detalhar essa discussão aqui. Remeto, todavia, o leitor ao livro de Adriana Cavarero, Vozes Plurais (2011), para a compreensão do percurso filosófico ocidental que privilegiou, para lograr as construções metafísicas, uma linguagem fundada no discurso silencioso da consciência e em paradigmas da visualidade, ao passo que recalcou os "perigos" do encantamento sonoro da voz.
} 
O que se deve perguntar hoje, todavia, é se a noção de linguagem como episteme é mesmo a única possível ou, ainda melhor, se é a mais representativa desse fenômeno que define o humano praticamente por antonomásia, tal como se esclarece na lapidar classificação aristotélica: zoon logon echon (o vivente que possui o logos). Em outras palavras, cabe perguntar se a noção de linguagem historicamente tomada como referência para a comparação com a música é mesmo a mais próxima do fenômeno linguístico em sua integralidade.

Nesse sentido, o que algumas correntes da filosofia da linguagem vêm se esforçando por caracterizar é que o aspecto produtivo (poiesis) ou cognitivo (episteme) da linguagem não é o único e nem mesmo pode ser tomado como seu principal traço constitutivo. A linguagem em seu todo - o que implica considerar não apenas os significados, o conteúdo, o texto, mas também o ato que os produz, a tomada da palavra, a voz - seria muito mais uma praxis. Como tal, a linguagem não depende de objetivos extralinguísticos nem é avaliada por eles; como praxis, a linguagem é uma atividade cujo fim se dá em si mesma.

Quem fala realiza uma ação que se finaliza em si mesma, da mesma forma que o ver e o respirar. Falamos, mas não porque constatamos que o uso da linguagem nos seja vantajoso, assim como vivemos, mas não porque julgamos útil a vida. (VIRNO, 2003, p. 18) ${ }^{3}$

As atividades cuja finalidade coincide inteiramente com a sua própria execução são consideradas "atividades sem obra". Elas não dão origem a um produto qualquer, durável, que exista por si mesmo. Em vez de objetos, tais atividades têm como único resultado o seu próprio desenvolvimento e dão vida apenas a um evento fugaz, único, contingente e irrepetível (VIRNO, 2003, p. 16).

3 Paolo Virno é ainda um autor relativamente pouco conhecido no Brasil, atualmente professor de filosofia da linguagem na Università Roma III. Um exame de suas obras permite aproximá-lo de um grupo de pensadores italianos, entre eles Giorgio Agamben, que aprofundam a noção de biopolítica. 
Como atividade sem obra, a linguagem, ao mesmo tempo em que se avizinha da ideia de praxis e se afasta relativamente da episteme e da poiesis, praticamente caracteriza-se como performance. Nessa condição, além de ter apenas a própria execução para exibir, consegue fazer sentido unicamente se vista ou escutada (recebida) por um outro, por um público: "a atividade sem obra implica sempre, por motivos estruturais, a exposição do agente ao olhar, e por vezes às reações severas, de seu próximo" (VIRNO, 2003, p. 16).

É interessante notar como o manejo dessas noções por Paolo Virno deriva da trama conceitual utilizada por Aristóteles em sua Ética a Nicômacos. Tratava-se, naquele caso, de estabelecer uma clara distinção entre a esfera da produção (poiesis) e a da ação (praxis). A primeira, dominada pela técnica, tem um objetivo externo e culmina na fabricação de um objeto. Fazem parte da esfera da produção, por exemplo, todas as artes não performáticas. Tendo sempre em mente não tanto o significado moderno, mas sobretudo a relação originária com as palavras fundamentais gregas (arte/techne; fazer, produzir, criar/poiesis; ciência/episteme; agir/praxis), é possível observar que o seguinte trecho do Livro VI da referida obra do Estagirita não deixa margem a dúvidas:

(...) a disposição pertinente à capacidade de agir é diferente da disposição racional pertinente à capacidade de fazer. Tampouco uma delas é parte da outra, pois nem agir é fazer, nem fazer é agir. Já que a arquitetura é uma arte e é essencialmente uma disposição racional da capacidade de fazer, e não há arte alguma que não seja uma disposição relacionada com fazer, nem há qualquer disposição relacionada com fazer que não seja uma arte, a arte é idêntica a uma disposição da capacidade de fazer, envolvendo um método verdadeiro de raciocínio. (...) Já que há diferença entre fazer e agir, a arte deve relacionar-se com a criação, e não com a ação. (ARISTÓTELES, 2001, p. 116)

Por outro lado, no campo da ação estariam o jogo e a prática ético-política, fundada na capacidade de deliberar e discernir:

(...) o discernimento não pode ser conhecimento científico nem arte; ele não pode ser ciência porque aquilo que se 
refere às ações admite variações, nem arte, porque agir e fazer são coisas de espécies diferentes. A alternativa restante, então, é que ele [o discernimento] é uma qualidade racional que leva à verdade no tocante às ações relacionadas com as coisas boas ou más para os seres humanos. De fato, enquanto fazer tem uma finalidade diferente do próprio ato de fazer, a finalidade na ação não pode ser senão a própria ação, pois agir é uma finalidade em si. (ARISTÓTELES, 2001, p. 117)

O próprio Paolo Virno destaca as afinidades da praxis política com as artes performáticas: contingência, efemeridade, ausência de um fim exterior, indistinção do "produto" das ações que o realizam, instituição necessária de uma esfera pública. E cita textualmente Hannah Arendt a propósito:

(...) as artes que não realizam "obra" alguma têm grandes afinidades com a política. Os artistas que as praticam dançarinos, atores, músicos e outros - têm necessidade de um público ao qual mostrar o seu virtuosismo, assim como os homens que agem politicamente têm necessidade de outros em cuja presença comparecem. (ARENDT apud VIRNO, 2003, p. 17) ${ }^{4}$

Tornando, enfim, à questão da linguagem e uma vez estabelecidas as suas afinidades com esfera da praxis, Virno, seguindo Émile Benveniste, diz que, tal como nos animais, a linguagem humana é uma atividade biológica, com a diferença fundamental de que ela não é de modo algum vinculada às configurações do ambiente. Por ser uma atividade que, insistase, tem seu fim em si mesma, a regulação da linguagem não pode advir de nenhuma esfera exterior; ela tem, necessariamente, de ser uma autorregulação. Em outras palavras, as regras arbitrárias da linguagem, a exemplo de todas as atividades sem escopo extrínseco, são, como também aponta Wittgenstein, naturais e necessárias. 0 funcionamento efetivo da linguagem assinala a indissociação de meio e fim, de execução e resultado.

\footnotetext{
${ }^{4}$ Não custa insistir que a palavra "arte", no trecho de Hannah Arendt, tem o sentido moderno a que estamos habituados, ao passo que, na tradução do texto de Aristóteles, ela guardava o sentido de "técnica", "habilidade para".
} 
Creio que, a esse ponto, a seguinte hipótese de Virno se torna muito instigante para pensar a música: para o filósofo italiano, a praxis linguística é o modelo de toda e qualquer atividade sem obra, é a matriz de toda e qualquer performance virtuosística particular. Ainda mais porque a linguagem tampouco tem um ponto de partida, um roteiro (como na música, aquilo que chamamos "obra"). 0 início da linguagem ou é a língua histórico-natural, sistema apenas virtual que ampara o discurso efetivo, ou é a pura indeterminação da faculdade de linguagem (noção a que retornaremos abaixo).

Seria o caso, nessas coordenadas, de desvincular, ao menos em termos essenciais, a linguagem de seu papel cognitivo de "busca de verdade", presente, por exemplo, quando se concede privilégio à correspondência biunívoca entre palavras e coisas, tal como ocorre na concepção de um Gottlob Frege, por exemplo. Frege, em seus estudos da linguagem, assinalava justamente o estatuto diferenciado de alguns enunciados que teriam, sim, Sentido (Sinn) intersubjetivo, mas não uma Denotação (Bedeutung) objetivamente acertável. É precisamente essa concepção que Virno combate, porque, ao colocar a exigência da denotação como prova de superioridade do ponto de vista cognitivo e projetar excessivamente a linguagem nessa perspectiva, Frege simplesmente abstrai uma série de outros elementos que são igualmente fundamentais e atuantes na linguagem.

\section{A faculdade de linguagem e o caráter ritual}

Além de caracterizar a linguagem como praxis e definila como $o$ modelo performático, outra elaboração de Paolo Virno pode ser útil para restabelecer em novas bases a relação da linguagem com a música. Recapitulando e desdobrando os ensinamentos de Ferdinand de Saussure, ele aponta que em todo enunciado existem dois aspectos fundamentais, simbióticos, mas bem distintos: 1) aquilo-que-se-diz: o conteúdo semântico expresso pelo enunciado graças a peculiaridades fonéticas, lexicais e sintáticas; 2) o-fato-que-sefala: o tomar a palavra, rompendo o silêncio; o ato de enunciar 
enquanto tal; a exposição do locutor aos olhos e ouvidos dos outros.

Aquilo-que-se-diz compreende toda a famosa relação langue/parole (língua e discurso) com a qual Saussure nomeou de um lado as oportunidades expressivas do sistema de uma língua histórico-natural e, de outro, a sua realização seletiva em um proferimento concreto.

Já o fato-que-se-fala foi acenado apenas brevemente pelo linguista suíço ao mencionar a faculdade de linguagem (faculté de langage), que significa: a genérica potência de enunciar, independentemente de qualquer língua determinada. Ora, justamente essa faculdade - lado apenas potencial (dynamis) e, ao mesmo tempo, biológico da linguagem - é o elemento capaz de distinguir o conceito de linguagem das específicas línguas histórico-naturais.

A faculdade de linguagem não é assimilada nem ao ato comunicativo em andamento (discurso, parole) nem à sua prefiguração virtual e sistemática (língua, langue). Ela atesta, no interior de cada enunciado, a potência de enunciar, a pura e simples possibilidade de dizer, a "dizibilidade". Virno demonstra como esses dois polos (aquilo-que-se-diz e fato-quese-fala), mais que reproduzir, fundamentam pares cruciais de grande fortuna filosófica, como empírico/transcendental ou ôntico/ontológico. Na raiz disso, o seguinte comentário:

Aquilo-que-se-diz representa ou institui estados de coisas do mundo (...). 0 fato-que-se-fala mostra, por sua vez, a inserção da própria linguagem no mundo, entendido aqui como contexto ou fundo de todos os estados de coisas e de todas as enunciações. Aproveitando uma célebre distinção de Wittgenstein, poder-se-ia dizer: o conteúdo semântico dá notícias sobre como é o mundo; a ação de enunciar indica bem mais, no momento em que nele se inscreve, que o mundo é. (VIRNO, 2003, p. 34)

Todavia, nosso autor aponta uma distinção ainda mais interessante: aquilo-que-se-diz indica a atitude comunicativocognitiva da linguagem, ao passo que fato-que-se-fala manifesta o seu caráter ritual. Ora, como não pode haver nenhum texto determinado (aquilo-que-se-diz) desvinculado do ato mesmo de 
sua produção (fato-que-se-fala), a consequência lógica é que não existe atividade cognitiva ou comunicativa dissociada de uma "tonalidade ritual". Na mesma linha de raciocínio, o falante se torna um fenômeno (phainesthai - aparecer) com a simples emissão da voz articulada, expondo-se aos olhos dos demais. E é nessa exposição, diz Virno, que consiste a inconfundível obra do rito.

Brevemente, vale dizer que o caráter ritual da linguagem é particularmente evidenciado em determinados tipos de asserção como o juramento. Detidamente estudado por Giorgio Agamben, ele é compreendido como um rito oral, que, não raro completado por um rito manual (gestos), coloca em jogo "não a função semiótica e cognitiva da linguagem como tal, mas sim a garantia da sua veracidade e da sua realização" (AGAMBEN, 2011, p. 12).

0 exemplo do juramento introduz um contraponto à 224 sensação cotidiana que temos da linguagem e à apreensão que dela fazemos. É que o senso comum rapidamente nos ilude, levando-nos a pensar que o funcionamento predominante e essencial da linguagem é exclusivamente ligado ao conteúdo, àquilo-que-se-diz. Apenas de maneira acessória e excepcional, para não dizer irrelevante, emergiria, quase imperceptível do fundo da linguagem, o fato-que-se-fala, que é relativo à faculdade de linguagem. Afinal, que utilidade teria apontarmos repetidamente para o simples ato de enunciar independente do conteúdo, para o evento da linguagem, para o fato de que falamos, de que temos voz? Embora velados pelo império do conteúdo semântico, são vários os momentos cruciais da experiência humana em que a linguagem se apresenta com as vestes, por assim dizer, mais humildes da mera faculdade de linguagem. Virno faz um pequeno elenco:

1) nas situações de risco, de perigo de extravio existencial, quando é necessário um recurso protetivo à antropogênese, isto é, à rememoração das etapas que a espécie, in illo tempore, e o indivíduo, em seu percurso de vida, percorreram para chegar aonde estão. É o caso da autoconsciência, que tantas vezes se mostra periclitante e não um pressuposto dado, e que, nesses momentos críticos, requer 
que o falante valorize o fato puro de que é capaz de falar, que represente a si próprio como alguém que fala, repetindo uma passagem crucial do processo de formação da autoconsciência em que nenhum tributo é pago a conteúdos semânticos;

2) na linguagem egocêntrica infantil, quando, livre do ônus comunicativo e denotativo, a criança pode experimentar a si mesma como fonte de enunciações.

A grande variedade de frases sem sentido e sem destinatário tem o escopo de iluminar a faculdade de produzir frases e o seu portador. 0 que se afirma no discurso egocêntrico? Nada além de 'eu falo' [o chamado performativo absoluto, estudado por John Austin]. Mas 'eu falo' é , ao mesmo tempo, base e ápice da autorreflexão. (VIRNO, 2003, p. 50)

3) em muito do que se classifica como função fática da linguagem (Jakobson), que chama a atenção para o fato de que se está falando simplesmente.

4) nos solilóquios adultos, em que evidentemente não se comunica nada a si mesmo além do próprio fato de que se é capaz de falar.

5) na palavra religiosa, em que o ato de enunciar, o tomar a palavra, como no caso da glossolalia em que os sons não são significantes, é um ato individualizante pelo qual o fiel exibe a inerência de um genérico poder-dizer ao seu singular e único corpo vivente.

\section{A voz (o som) na linguagem}

Um aspecto, evidentemente ligado aos demais, que vale a pena ser ressaltado nas elaborações de Virno sobre a linguagem e que, a meu ver, tem também repercussões sobre o modo como consideramos a relação com a música, diz respeito mais especificamente ao elemento eminentemente sonoro da linguagem, a voz. A voz foi tradicionalmente o elemento mais recalcado da linguagem no percurso ocidental, desprezada em proveito da linguagem interna e silenciosa da consciência. Outra filósofa italiana, Adriana Cavarero, no livro Vozes Plurais (2011) demonstra exatamente o tratamento devotado à voz 
pelo pensamento ocidental, caracterizando-o de maneira emblemática: a filosofia se estabeleceu "tapando os ouvidos". Ou seja, privilegiando na constituição de seu discurso e de suas bases tudo o que era insonoro e interno - o reino dos significados visíveis - relegando à voz um papel absolutamente residual e insignificante. Na metafísica ocidental, diz Cavarero, com foco nítido em Descartes, "o pensamento não tem voz, não invoca nem fala: cogita".

Virno, em perspectiva muito semelhante (visto que lhe interessa o momento em que o "verbo se faz carne" - título de seu livro), embora com propósitos distintos, colhe alguns deslizes sintomáticos de pensadores que se traem ao insistirem justamente no comportamento flagrado por Cavarero: tapar os ouvidos em relação à voz. Num primeiro caso, cita Vygotsky que, ao especificar o herdeiro do solilóquio infantil no adulto, aponta exclusivamente o monólogo interior do pensamento verbal silencioso, desprezando justamente o fato-que-se-fala, o ato mesmo de enunciação, a tomada da palavra, todos aspectos relativos à faculdade de linguagem e radicados no proferimento vocal e sonoro. Para Virno, porém, "a vocalização não é um caráter marginal da linguagem egocêntrica: a sua eliminação altera e empobrece o significado integral do fenômeno." (VIRNO, 2003, p.55)

E mais adiante:

O erro de Vygotsky está em considerar escórias ininfluentes os traços característicos do monólogo infantil que o pensamento verbal não inclui em si. Ele despreza o papel lógico da voz e o seu alcance ritual. Em relação à linguagem egocêntrica, a 'linguagem interna' figura como uma abreviação redutora e infiel. (VIRNO, 2003, p. 56)

Além de Vygotsky, Virno analisa também um preconceito semelhante por parte de Husserl quanto aos momentos em que o falante fala consigo mesmo. Para o pensador alemão, quando falamos em voz alta conosco, não estaríamos realmente falando, mas limitando-nos a realizar uma operação um tanto bizarra: não fazemos nada além de representar-nos como pessoas que falam e que comunicam. A questão, diz Virno, é que: 
[essa representação] não é parasitária ou extravagante, mas constitui um aspecto inescapável, ainda que no mais das vezes inadvertido, de toda enunciação. 0 ponto crucial é que o indivíduo intencionado a monologar em voz alta isola esse aspecto e o ostenta abertamente. No solilóquio bem escandido, justamente porque desaparece todo impulso comunicativo, é representado o fato-que-se-fala. Exonerada de específicas tarefas informativas, a voz significante dá notícias, teatralmente, sobre a faculdade de linguagem. (VIRNO, 2003, p. 58)

\section{Música e linguagem em novas bases}

Para o que aqui nos interessa, a concepção de linguagem que emerge das considerações de Paolo Virno é muito mais próxima à música do que aquela que privilegiava sobremaneira o aspecto cognitivo. Acima de tudo, trata-se de uma perspectiva mais integral, que não filtra a linguagem de aspectos que só podem ser considerados residuais e desprezíveis numa ótica já comprometida com a tradição logocêntrica. Questionado o logocentrismo, eles emergem como elementos inerentes e constituintes do fenômeno linguístico, de igual direito ao que tem o conteúdo semântico. E é realmente interessante notar que tudo o que foi depurado da linguagem no processo que privilegiou a sua função cognitiva é exatamente o que mais aproxima linguagem e música: a ritualidade, o elemento sonoro vocal, o caráter performativo. Resulta evidente, de tudo o que se disse até aqui, a importância de revisitar criticamente os pressupostos e fundamentos da concepção de linguagem, pois é também deles que deriva a incontestável perda de significância da música, da dimensão acústica, no edifício do saber ocidental.

Por outro lado, falar de praxis, de ritual, da potência da faculdade de linguagem, do elemento vocal e sonoro abre horizontes de aproximação muito mais vastos e instigantes para uma abordagem comparativa com a música do que simplesmente identificar e enfatizar, digamos, a lacuna semântica das obras musicais. 
De certa maneira, é possível localizar no campo musical avanços que espelham essa abordagem. Penso na consciência e valorização crescente dos estudos sobre a voz em geral, culminando, no âmbito da Educação Musical, com uma intensa atenção à dimensão vocal não necessariamente associada a um treinamento de ordem técnica e profissionalizante. Penso também no interesse crescente pelas questões da Performance e do Ritual nos estudos etnomusicológicos e musicológicos, que tudo tem a ver com a noção de praxis. Os estudos da Interpretação e da Performance Musical também parecem avançar para esse terreno - aqui tenho em mente as formulações de Nicholas Cook sobre "processo e produto", entre várias outras. A musicologia, de modo geral, na trilha do entendimento da música como forma de ação comunicativa e expressiva, de alguma maneira se aproxima, conscientemente ou não, daquela perspectiva delineada por Hannah Arendt, pela qual a música, na qualidade 228 de arte performática, tem claras afinidades com a política. Por esse caminho, por exemplo, torna-se muito pertinente abordar as múltiplas apropriações da música no espaço contemporâneo e as negociações que se fazem em torno de sua produção, uso, recepção e valoração.

O que, de todo modo, parece lacunar é uma avaliação sistemática dos princípios que regem todas essas novas perspectivas para os estudos musicais. Quero crer que tal tarefa deveria estar a cargo da Filosofia da Música que, no entanto, não vem dando mostras de querer acolher o desafio.

De um lado, tal lacuna impede uma visão menos técnica e disciplinar quanto ao alcance de uma reaproximação em novas bases da relação entre linguagem e música. 0 risco é de permanecermos presos a visões muito setorizadas em que uma articulação de maior envergadura, mais sintética e que dê conta da complexidade entre as várias questões que vêm emergindo nas disciplinas mencionadas não seja viabilizada. Por outro lado, perde-se, como indiquei anteriormente, a oportunidade de questionar de maneira decisiva o lugar que a cultura reservou à música no desenrolar de suas escolhas e vicissitudes históricas, lugar que, distante do privilégio tradicionalmente reservado a um logos desvocalizado e às suas 
construções mentais e silenciosas, foi aceito e socialmente assumido como a região da insignificância, do entretenimento, da superficialidade, com todas as marcas sociais que daí decorrem. Em suma, deixa-se de discutir a importante relação entre música e conhecimento ou, em outra formulação, a questão da música como saber.

\section{Referências bibliográficas}

AGAMBEN, Giorgio. O sacramento da linguagem; arqueologia do juramento. Belo Horizonte: UFMG, 2011.

ARISTÓTELES. Ética a Nicômacos. 4⿳亠丷a ed. Trad. Mario da Gama Kury. Brasília: UNB, 2001.

BARONI, Mario. L'ermeneutica musicale, In: NATTIEZ, Jean-Jacques (org). Enciclopedia della Musica v.2 (Il sapere musicale). Torino: Einaudi, 2002, p.633-658.

BONDS, Mark Evan. Absolute Music; The History of an Idea. New York: Oxford University Press, 2014.

COOK, Nicholas. Entre o processo e o produto: a música enquanto performance. Permusi. Belo Horizonte, no 14, 2006, p.5-22.

CAVARERO, Adriana. Vozes plurais; filosofia da expressão vocal. Trad. Flavio Barbeitas. Belo Horizonte: UFMG, 2011.

HANSLICK, Eduard. Do belo musical. Trad. Nicolino Simone Neto. 2. ed. Campinas: Unicamp, 1992.

NUNES, Benedito. Crivo de papel. 2. ed. São Paulo: Ática, 1998.

VIRNO, Paolo. Quando il verbo si fa carne; linguaggio e natura umana. Torino: Bollati Boringhieri, 2003. 